\title{
O GAÚCHO NA TRADIÇÃO REORDENADA
}

Daysi Lange Albeche*

Do ponto de vista simbólico as representações míticas podem ser utilizadas como objeto de estudo, pois constituem documentos do imaginário de um determinado contexto histórico. De acordo com esse contexto a finalidade e o sentido destas representaçốes passam a nos revelar idéias e valores de um grupo social perante sua época.

Ao analisarmos as imagens criadas pela expressão literária e pelo discurso da ditadura científica positivista no período da República Velha no Rio Grande do Sul identificamos que o mito do gaúcho teve diferentes significados.

A imagem do gaúcho para o PRR (Partido Republicano Rio-Grandense) pertencia à tradição reordenada, tendo como referencial a Revolução Farroupilha, 1835/45. Porém, esta imagem elaborada pelo PRR guarda um significado que busca homogenizar realidades totalmente diferentes.

No período da Revolução Farroupilha o termo gaúcho mantinha um sentido pejorativo, pois segundo análise de Flores este designava:

"(...) o componente de um grupo social formado por índios, negros fugidos, desertores, bandidos e vagabundos, que habitavam a campanha do Rio Grande do Sul, do Uruguai e da Argentina."1

* Professora Mestre em História - PUCRS

1 FLORES, Moacyr. República Rio-Grandense, Realidade e Utopia. Porto Alegre:

Tese de Doutorado PUCRS, 1992, p. 349. 
O gaúcho era componente de um grupo social marginalizado pela sociedade, pois não possuía propriedade, cidadania e o emprego dependia do período de safra.

Logo, para compreendermos o significado do termo gaúcho no discurso do PRR, devemos ressaltar que elementos foram propostos como fatores de ordem social, bem como quais foram os símbolos e mitos aceitos durante a implantação do regime republicano no Rio Grande do Sul.

Pelo discurso o PRR definiu interesses e objetivos a alcançar. Este por ser normativo e punitivo apregoou a necessidade de todos os elementos sociais subordinarem-se a norma coletiva. Mostrando-se como únicos intérpretes do conhecimento os republicanos implantaram um Estado Policial, que não aceitou críticas e desordens sociais.

"(...) o positivismo não reconhece a ninguém outro direito senão o de cumprir sempre o seu dever (...) O positivismo não admite nunca senão deveres de todos para com todos; pois que seu ponto de vista sempre social não pode comportar nenhuma noção de direito, constantemente fundada na individualidade. ${ }^{2}$

Apoiando-se no mito da utopia industrial doutrinaram sobre a predominância da organização social, o tempo de trabalho, a divisão de tarefas e as normas rígidas a serem cumpridas.

A organização da ditadura científica positivista baseou-se no pensamento racionalista de Auguste Comte. Júlio de Castilhos e o PRR reinterpretaram e adaptaram os elementos simbólicos da sociedade positivista, como etapa final de uma evolução, que seria o Tempo de Ouro de ordem, progresso, felicidade, liberdade e justiça. A efetivação do Estado Positivo dependeria de:

- implantar a homogenização social como representante da verdadeira força social dirigida pela mesma comunhão de interesses e sentimentos;

- identificar Júlio de Castilhos e o PRR como únicos guardiões da Ordem e Progresso, sustentando a idéia que somente a elite esclarecida seria capaz de conduzir o estabelecimento da ordem republicana, representando e dirigindo os interesses de todos os indivíduos da sociedade;

- justificar a "cientificidade" da Constituição Rio-Grandense de 1891 como garantia da evolução da Humanidade;

2 COMTE, Auguste. O Catecismo Positivista. In: Os Pensadores, v. 33, São Paulo: Abril Cultural, 1973, p. 263. 
- apoiar o surgimento do homem coletivo.

No sentido de propagandearem suas idéias e princípios, bem como indicar a ditadura científica positivista como "verdadeiro" regime de liberdade e justiça os republicanos utilizaram da idéia comtiana da criação de festas e datas cívicas. Um exemplo disto foi a criação do Grêmio Gaúcho de Tradição, 1898, por João Cezimbra Jacques. A agremiação, juntamente com a Força Policial, atuaram na propaganda e justificação da ordem republicana no Rio Grande do Sul.

A Força Policial controlava pelo uso da força quaisquer desordens que viessem atrapalhar o desenvolvimento da Ordem e Progresso. O soldado deveria ser disciplinado e cumpridor de seus deveres para defender as instituições da justiça e da liberdade. O Corpo Policial tinha duas atribuições: a polícia judiciária e a administrativa.

"(...) a administrativa exerce a vigilância que previne os perigos e os delitos e a polícia judiciária tem o encargo de rastrear o crime, coligir, provar e capturar delinqüentes." ${ }^{3}$

O Grêmio Gaúcho de Tradição contribuiu com a propaganda republicana castilhista, através da prática do culto cívico "à memória dos grandes homens públicos que prestaram serviços notáveis à Pátria" ${ }^{4}$ para deles retirar os exemplos de ordem moral e material a serem zelados pela sociedade. Em suas comemorações regulares idealizou-se a tradição modelar de "homens alegres e generosos" e ao mesmo tempo "altivos e enérgicos" ${ }^{55}$ sempre coincidentes com "a evolução da história republicana" no Rio Grande do Sul e do tempo de glória dos antepassados farroupilhas.

O princípio comtiano do culto ao passado, onde o "presente glorifica o passado para melhor preparar o futuro", ${ }^{6}$ manifestou-se na agremiação também nos feriados e nas datas cívicas com a prática de "exercícios físicos e costumes da atualidade" ${ }^{77}$ com especial atenção aos grandes feitos do passado. Estes de acordo com a idéia da educação cívica, isto é, de aproveitar só o que é útil. ${ }^{8}$

A FEDERAÇÃO. Porto Alegre, 22 ago. 1895.

4 A FEDERAÇĀO. Porto Alegre, 26 set. de 1910.

5 JACQUES, Joảo Cezimbra. Assumptos do Rio Grande do Sul. Porto Alegre: Oficinas Gráficas da Escola de Engenharia, 1912, p. 38.

6 COMTE. Op. cit. p. 171.

7 JACQUES. Op. cit. p. 59.

8 Vide $A$ Federação. Porto Alegre, 18 nov. 1912 e 21 set. 1925. 
"Sociedades como a nossa nobre agremiação devem considerar-se verdadeiras oficinas cuja arte é cultivar tudo quanto na tradição há de alegre, bom, moralizador, salutar, lhano e sincero, ou em uma palavra, todos os elementos que constituem o que ela tem de grandioso, e tudo, enfim, quanto dentro dos limites do possível e da ordem, possa concorrer para o engrandecimento de nossa Terra (...)."

As festas, comemorações e estatutos da agremiação visando a educação cívica, elogiavam as mais diversas datas como a dos veteranos da Guerra do Paraguai, a da Proclamação da República Brasileira e o 20 de setembro no intuito de relembrar os legendários de 1835 e principalmente a instalação do regime republicano castilhista como reavivador dos ideais farroupilhas antes adormecidos, atribuindo assim importância à moral, ao estudo científico e à Constituição de 14 de Julho de 1891 como elementos geradores de Ordem e de Progresso.

Seguindo o catecismo positivista, "o fim contínuo da vida humana é a conservação e o aperfeiçoamento do grande ser". ${ }^{10} \mathrm{O}$ discurso republicano utilizou a Revolução Farroupilha como modelo do qual poder-se-ia retirar as melhores regras de conduta moral a serem transmitidas às gerações presentes e futuras, pois compreender a moral representava ter conduta cívica. Júlio de Castilhos e o PRR passaram a ser o elo legítimo dos ideais de 1835 , reinterpretando assim, o núcleo simbólico de um Tempo de Ouro pela idealização de uma tradição reordenada. A Epopéia Farroupilha tornou-se modelo dos valores de ordem, progresso, generosidade, liberdade, bravura, sabedoria e justiça de que o partido republicano dizia-se continuador.

"(...) é relevo para legitimar a existência do Part. Republicano, mantenedor da continuidade histórica, em respeito ao passado, de cujas lições aproveita a ação dos continuadores (...) A comemoração do 20 de Setembro não deve ter outro sentido, significado que o passado é a fonte em que o presente se inspira para delinear o futuro". ${ }^{11}$

Após a morte de Castilhos, 24 de outubro de 1903, o culto ao herói se direcionou à sua pessoa. Júlio de Castilhos é mostrado como um

9 JACQUES. Op. cit. p. 65.

10 COMTE. Op. cit. p. 196.

11 ROSA, Othelo. Júlio de Castilhos - Perfil Biográfico e Escritos Políticos. Porto Alegre: Globo, 1930, p. 135. 
homem eleito e portador de uma grande cultura, ocorrendo a necessidade de sua "glorificação". E para isto, cada vez mais, a sociedade deveria repetir e preservar os exemplos prestados pelo grande líder.

"É para os grandes, para os fortes é para os justos a glória de morrer...

Para Castilhos como para todos os grandes homens a morte foi a justiça foi a apoteose, foi a glorificaçāo." ${ }^{12}$

Com a "glorificação", Castilhos passa a ser tratado não como um homem comum, pois estaria sujeito às leis da natureza, mas como um grande herói sendo dispensado de qualquer questionamento, crítica e avaliação de sua conduta. Neste período a ditadura científica positivista procura manter o mito do herói Júlio de Castilhos de acordo com a doutrina comtiana do culto ao passado, transformando a história num efeito acumulativo dos exemplos dos grandes homens. Castilhos é apresentado como continuador e consolidador do tempo áureo, a tradição reordenada.

"Os vivos são sempre, e cada vez mais, governados necessariamente pelos mortos." ${ }^{13}$

Segundo o PRR os ideais de Liberdade, Igualdade e Humanidade do tempo da Revolução Farroupilha não se efetivaram, pois faltara a homogenização social proporcionada pela formulação de um código de leis conciliador da Ordem e do Progresso. Por isso, o herói Bento Gonçalves não é considerado Patriarca, este título coube a Júlio de Castilhos, apresentado como propagandeador, organizador e consolidador da República dentro dos "científicos" princípios do "aperfeiçoamento do grande ser" (O Estado Social).

\footnotetext{
"(...) Se os farrapos, nos seus arrancos de valor épico, foram a aurora antecipada dos dias de hoje, em sua fruste mas generosa tentativa, Júlio de Castilhos foi o construtor prático de seus ideais, com a força de um gênio de vidente, com seu estupendo labor sem interregnos e sem desfalecimentos. (...) Porto Alegre é hoje um laboratório de cultura científica, onde os rio-grandenses encontram meios de se educarem, sem grandes dispêndios de outros tempos, que só os abandonados podiam enfrentar. ${ }^{14}$
}

12 ROSA. Op. cit. p. 325.

13 COMTE. Op. cit. p. 136.

14 A FEDERAÇÃO. Porto Alegre, 20 set. 1910. 
A mitificação aos traços heróicos de Castilhos tornaram-no despossuído de falhas e defeitos. O verdadeiro batalhador das antigas aspirações republicanas que foram desejadas pelos farroupilhas, mas que frente ao regime monárquico não conseguiram se concretizar. Com a "glorificação", Júlio de Castilhos foi igualado à "própria tradição" rio-grandense. Essa mitificação também indicou o PRR como o partido guardião da verdade e do conhecimento. Perante os adeptos da tradição reordenada, Júlio de Castilhos era o único rio-grandense que reunia todos estes qualificativos. Os exemplos dessas virtudes se destacavam em seu trabalho dedicado à propaganda, implantação e consolidação da República no Rio Grande do Sul. Fora o exemplo, em vida e de luta por um ideal: a implantação da República na Pátria Brasileira. Assim, deram-lhe títulos de Guia Capaz, ${ }^{15}$ Patriarca, ${ }^{16}$ Cavaleiro Andante da República. ${ }^{17}$

Todas as atribuições qualificativas que acompanham e exaltam Castilhos referem-se aos atos políticos e aos trabalhos jornalísticos, nos quais atuou como propagandista, polemista e chefe do PRR, bem como evangelizador do ideal republicano. De acordo com o discurso castilhista, a "glorificação" de Júlio de Castilhos, tornava-o um guia imortal devendo ficar sempre presente na lembrança de todos os "bons republicanos", pois seus atos, nome, procedimentos, decisões foram modelares e sem mácula.

"(...) ele é então, no Rio Grande do Sul, o monitor, que admoesta; o mestre, que ensina; o sacerdote, que aconselha; o patriarca, em fim, na acepção mosaica de chefe do povo."18

Porém, o discurso da norma coletiva, festas, rituais cívicos e romarias, não conseguiram perpetuar oficialmente, após 1930, o mito do herói Júlio de Castilhos como símbolo da sociedade rio-grandense. O mito de Júlio de Castilhos foi um signo criado a partir de relações conhecidas, sendo imposto por um pequeno grupo social, o que fez tornar-se diferenciado e único, entretanto não representando as aspirações da maior parte da população.

O culto à memória do herói republicano condensa-se no monumento a Júlio de Castilhos, na praça Marechal Deodoro. 


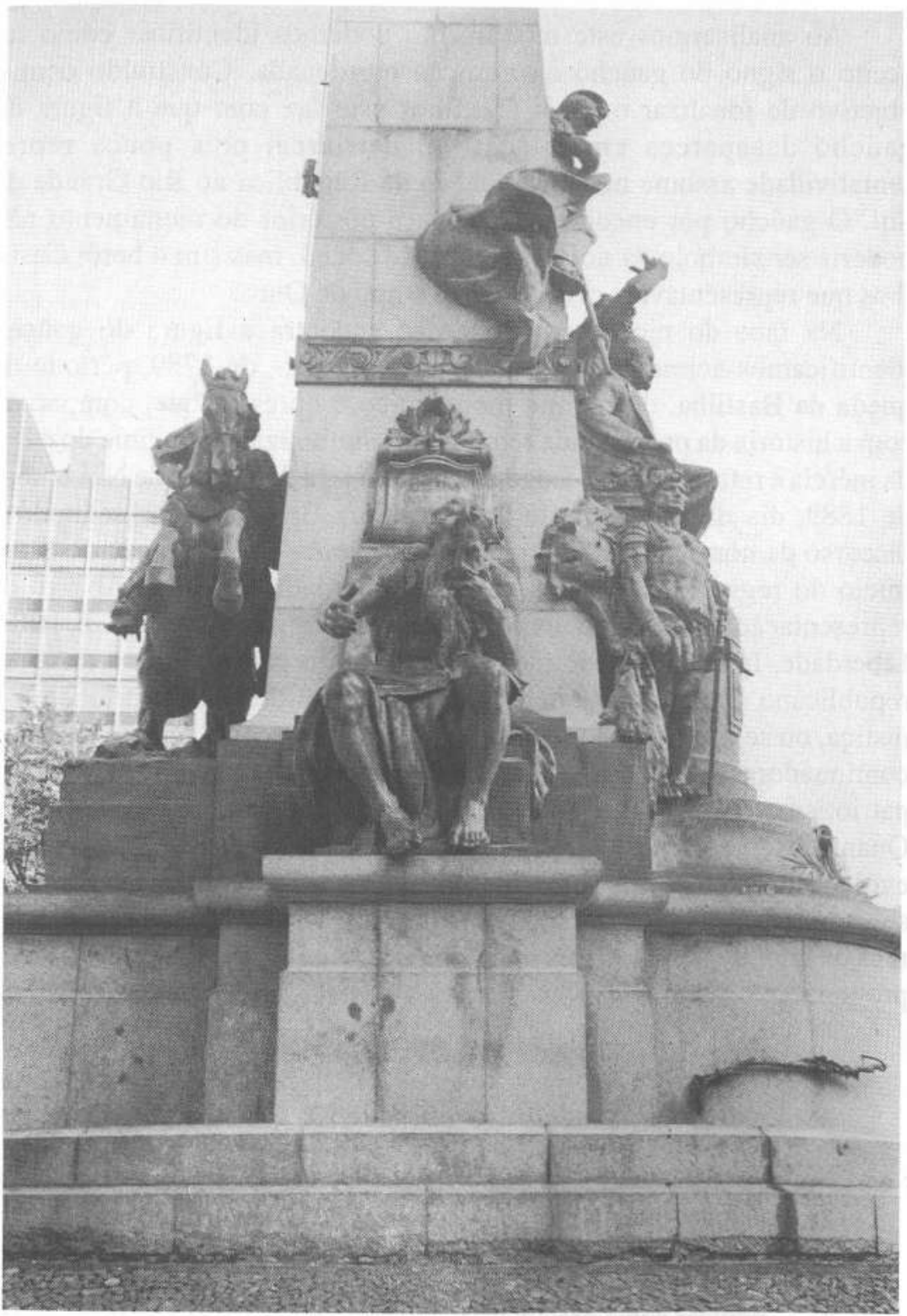

Fig. 01 - A glorificação do herói republicano Júlio de Castilhos deveria ser guia e modelo para as geraçōes presentes e futuras Monumento a Júlio de Castilhos na praça Marechal Deodoro, Porto Alegre. 
Ao analisarmos este monumento podemos identificar como foi aceito o signo do gaúcho na tradição reordenada. Construído com o objetivo de idealizar o herói Castilhos este faz com que a figura do gaúcho desapareça em relação ao Patriarca, pois pouca representatividade assume na consolidação da República no Rio Grande do Sul. O gaúcho por encontrar-se na face posterior do monumento não poderia ser símbolo da nova organização social, mas sim o herói Castilhos que representava a evolução, o Tempo de Ouro.

$\mathrm{Na}$ face do monumento onde se encontra a figura do gaúcho identificamos acima de sua representação a data de 1789 , período da queda da Bastilha, do regime monárquico e opressor que, comparado com a história da propaganda republicana simbolizava o regime do çãos, da inércia e retrogradação. Logo abaixo, temos a data de 15 de Novembro de 1889, dia da Proclamação da República Brasileira que segundo o discurso da norma coletiva republicana foi para o Rio Grande do Sul o início do regime de todas as virtudes, liberdade e justiça. Abaixo da representação do gaúcho temos o escudo Farroupilha com o lema: Liberdade, Igualdade e Humanidade. Assim, o gaúcho para o discurso republicano foi cultuado pelo seu caráter de bravura, patriotismo e justiça, ou seja, a tradição reordenada da qual os republicanos se diziam continuadores. Segundo o PRR o gaúcho tornou-se arquétipo de civismo, patriotismo, coragem, lealdade, bravura, justiça, ordem e moralidade. Quanto à representação do gaúcho a cavalo esta estava de acordo com a evolução social aceita pelos positivistas, pois simbolizava a bravura selvagem em lances arriscados do lendário homem dos campos. Costumes de um passado morto que a civilização condenou em nome da lei do progresso e do "conservar melhorando".

"Para o rio-grandense a palavra gaúcho significa hoje uma tradição, uma síntese expressiva e cara de uma página do nosso povo, fase de nossa vida passada (...) Quase extinto já, o homem do campo capaz de merecer o nome de gaúcho, com a sua acepção literal, é raro, raríssimo, em nossos dias, pois a civilização penetrou os nossos pampas transformando os costumes (...) A civilização condenou os costumes desse passado morto em nome da delicadeza das maneiras e elegância do porte, a grande lei do progresso repudiou as suas práticas como prejudiciais ao surto das indústrias, (...) Esta palavra é, pois, a evocação justa de um passado que não deve reviver." ${ }^{19}$

19 A FEDERAÇÃO. Porto Alegre, 12 abr. 1912. 


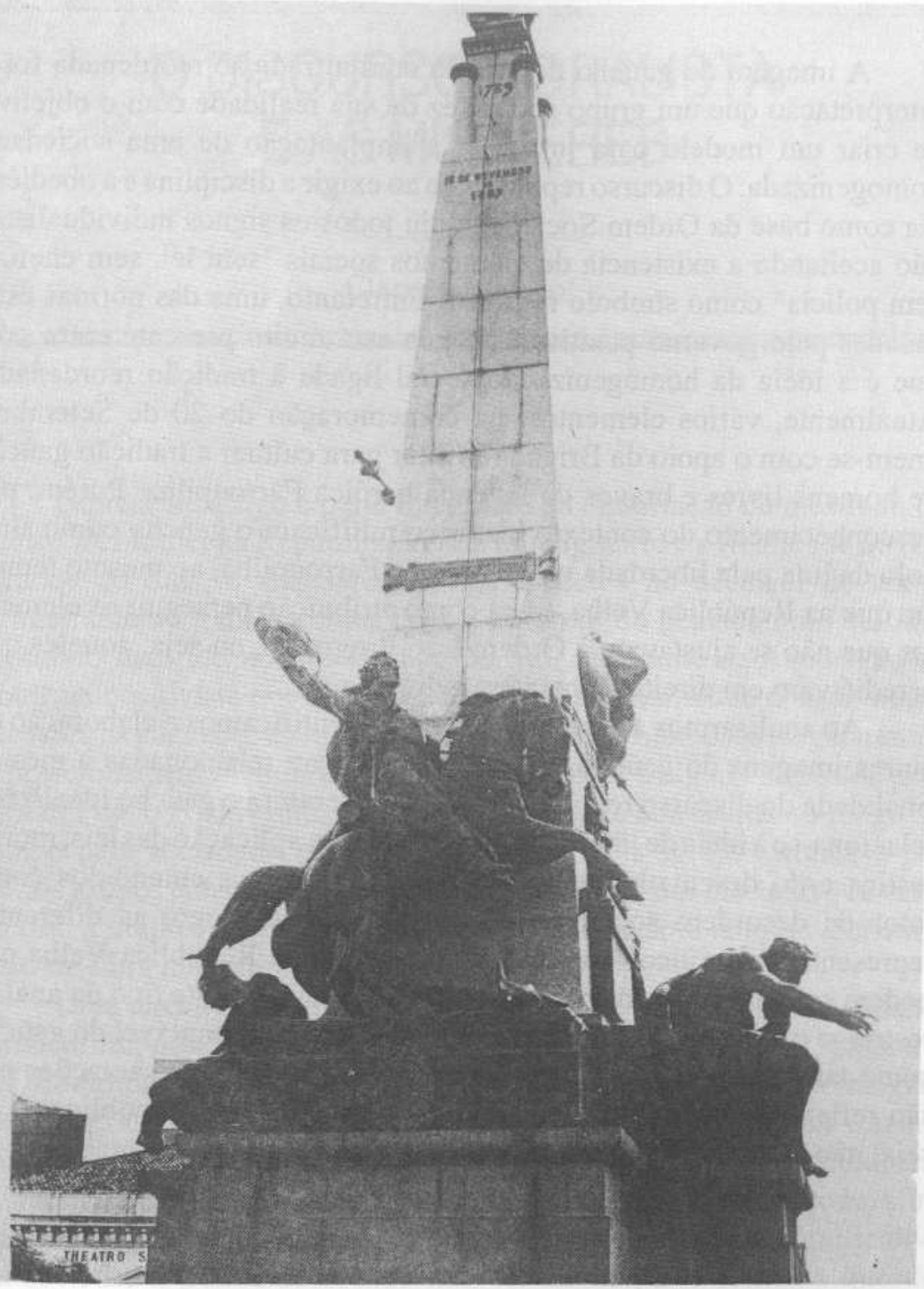

Fig. 02 - O Gaúcho na tradição Reordenada.

O gaúcho do discurso da norma colctiva republicana é o da tradição reordenada. $\mathrm{O}$ arquétipo de civismo, bravura, honra, justiça e liberdade de um tempo de glórias que o herói Júlio de Castilhos soube reviver com a implantação da ditadura científica positivista. Monumento a Júlio de Castilhos na Praça Marechal Deodoro, Porto Alegre. 
A imagem do gaúcho de acordo com a tradição reordenada foi a interpretação que um grupo social fez de sua realidade com o objetivo de criar um modelo para justificar a implantação de uma sociedade homogenizada. O discurso republicano ao exigir a disciplina e a obediência como base da Ordem Social excluiu todos os signos individualistas não aceitando a existência de elementos sociais "sem lei, sem chefe e sem polícia" como símbolo regional. Entretanto, uma das normas estipuladas pelo governo positivista, ainda está muito presente entre nós, que é a idéia da homogenização social ligada à tradição reordenada. Atualmente, vários elementos, na comemoração do 20 de Setembro, unem-se com o apoio da Brigada Militar para cultuar a tradição gaúcha de homens livres e bravos da legenda heróica Farroupilha. Porém, por desconhecimento do contexto histórico mitificam o gaúcho como símbolo da luta pela liberdade na Revolução Farroupilha, ao mesmo tempo em que na República Velha, tinha como atribuição perseguir os elementos que não se ajustavam à Ordem e ao Progresso, ou seja, aqueles que acreditavam em direitos e paixões individuais.

Ao analisarmos a literatura da época identificamos a elaboração de outras imagens do gaúcho e essas não estavam relacionadas à mesma finalidade do discurso republicano. Nessa literatura o gaúcho idealizado relaciona-se à idéia de liberdade questionando a aplicação das leis, moral, justiça e do desenvolvimento material. ${ }^{20}$ Elementos entendidos como fator de desordem social no discurso do PRR. Logo, as diferentes representações míticas do gaúcho no período da República Velha não podem ser analisadas através de um único discurso. Este tipo de análise restringe o significado mítico gerando uma imagem imutável do gaúcho como também não leva em consideração que essas representações não são reflexo do social privilegiado pela norma coletiva republicana, ou seja, não a confirmam e muitas vezes sugerem sua transformação.

20 ALBECHE, Daysi Lange. Imagens do Gaúcho: História e Mitificação. Porto Alegre: Dissertação de Mestrado, PUCRS, julho de 1995. 